\title{
Clinical Applications of Pediatric Pulmonary Function Testing: Lung Function in Recurrent Wheezing and Asthma
}

\author{
Jason Debley, M.D., M.P.H., ${ }^{1}$ Amy G. Filbrun, M.D., M.S., ${ }^{2}$ \\ and Padmaja Subbarao, M.D., M.Sc. (Epid), $\operatorname{FRCP}(C)^{3}$
}

Pulmonary function testing remains the gold standard for the diagnosis and management of wheezing disorders in older children and adults. Although wheezing disorders are among the most common clinical problems in pediatrics, most young children and toddlers cannot perform most of the currently clinically available pulmonary function tests. In this article, we review the different types of pulmonary function tests available and discuss the applicability and utility in the different age groups with specific reference to suitability in the diagnosis and management of wheezing disorders.

\section{Introduction}

A STHMA IS A chronic reversible obstructive airway disease. In school-age children objective measurement of lung function is essential to the diagnosis and evaluation of asthma, as medical history and physical examination are not reliable means of assessment. ${ }^{1}$ Although clinicians are generally able to identify airflow obstruction clinically, ${ }^{2}$ they are unable to assess the degree or reversibility of the airflow obstruction. ${ }^{3}$ In a recent study, up to a third of children with moderate-to-severe asthma were reclassified to a more severe asthma category when spirometry was assessed in addition to symptom frequency. ${ }^{4}$ In contrast, another study found that most children with mild-to-moderate asthma by symptom classification were found to have normal lung function by $\mathrm{FEV}_{1}$ [forced expiratory volume in one second (spirometry)]..$^{5}$ These seemingly contradictory findings emphasize the importance of including pulmonary function testing (PFT) in a comprehensive assessment of asthma.

Recurrent wheezing affects $20 \%-30 \%$ of infants and toddlers, yet resolves in at least half of these children by school age. Eighty percent of school-age children with persistent asthma were symptomatic by age 6 years, with more than half symptomatic by age 3 years. ${ }^{6}$ However, differentiating transient wheezing from persistent asthma in the early years is problematic since the 2 syndromes have only been described epidemiologically. Therefore, practical methodologies to objectively assess lung function in infants and toddlers for the purposes of accurately diagnosing asthma are highly desirable.
In this review, we will attempt to concisely review the literature of currently available pulmonary function techniques in children to assist in the diagnosis and management of asthma and recurrent wheezing.

\section{Spirometry \\ Childhood}

Spirometry is the gold standard for the diagnosis and management of asthma. It is the most commonly used method to assess lung function. Recent NIH guidelines ${ }^{7}$ recommend the use of spirometry, specifically $\mathrm{FEV}_{1}$ and $\mathrm{FEV}_{1} / \mathrm{FVC}$ [forced vital capacity (spirometry)] ratio for the diagnosis and management of children older than 5 years. This is in part due to the fact that pulmonary function has been found to be more sensitive than clinical examination ${ }^{2,3}$ or symptoms for the detection of obstructive pathology. ${ }^{4}$ The greatest value in diagnosing asthma with the use of spirometry is the documentation of reversibility with short acting bronchial agonist. The degree of reversibility has been correlated with the degree of airway inflammation ${ }^{8}$ and postbronchodilator measures can be used to follow lung growth and remodeling. ${ }^{9}$ Further, those children with the greatest reversibility with a short acting bronchial agonist are most at risk for remodeling and loss of lung function over time. ${ }^{10}$

Other factors making spirometry a useful test in the assessment of asthma and bronchodilator response (BDR) include portability of the measurement device, ease of use for the operator, and repeatability of the maneuver. Spirometry

\footnotetext{
${ }^{1}$ Seattle Children's Hospital, University of Washington, Seattle, Washington.

${ }^{2}$ C.S. Mott Children's Hospital, University of Michigan, Ann Arbor, Michigan.

${ }^{3}$ Hospital for Sick Children, University of Toronto, Toronto, Ontario, Canada.
} 
is the least variable of the pulmonary function maneuvers currently commercially offered in most clinical laboratories. The coefficient of variation for $\mathrm{FEV}_{1}$ ranges from $2.7 \%$ to $5 \%$, whereas the variability of other measures such as specific airway resistance (sRaw), respiratory resistance during interruption (interrupter resistance) (Rint), and respiratory impedance (forced oscillation technique) (Xrs) are at least double to triple. ${ }^{11,12}$ This low coefficient of variation would suggest that $\mathrm{FEV}_{1}$ would be the most sensitive test to detect BDR; however, most studies have not assessed the betweenoccasion repeatability in disease states. ${ }^{13}$ Only 1 study in adults studied this phenomenon and suggested that the variability of $\mathrm{FEV}_{1}$ was significantly higher in disease states, thus suggesting that other measures may be more sensitive to BDR assessment. ${ }^{13}$ This conclusion requires further study.

Other limitations of $\mathrm{FEV}_{1}$ relate to the physiology underlying its measurement. Asthma is primarily a disease of the small airways ${ }^{14}$ and studies in well-controlled asthmatics have shown continued obstruction and airway inflammation in the small airways despite normal measures of the large airways. The $\mathrm{FEV}_{1}$ may remain preserved despite significant small airway obstruction, and hence the need for more sensitive measures of small airway obstruction. This is an active area of research and may in the near future lead to the development of novel strategies to monitor disease progression.

At the current time, $\mathrm{FEV}_{1}$ remains the most studied lung function measure in asthma and remains the most recommended physiological assessment for the diagnosis and management of wheezing disorders in childhood.

\section{Preschool children}

Children as young as 3 years of age are capable of performing spirometry under ideal laboratory conditions when trained by technicians skilled in performing spirometry in this age group. In 2007 the American Thoracic Society (ATS) and European Respiratory Society (ERS) published a statement that included technical recommendations for the performance of spirometry in preschool children to facilitate comparison of data between centers. ${ }^{11}$ Several studies describing spirometric data in healthy preschool-age children have been published over the past decade, ${ }^{15-18}$ and recently Stanojevic et al. published robust reference equations for children ages 3 through 7 years based on an analysis of preschool lung function data from 3,777 children collated from 15 centers in 11 countries. ${ }^{19}$

An important limitation to clinical use of preschool spirometry is the lack of repeatability data, thus limiting interpretations of change in lung function following a clinical intervention, such as response to bronchodilators or corticosteroids. Another practical limitation is the feasibility of obtaining measurements in a busy clinical practice. Recently, Gaffin et al. conducted a real-world assessment of preschool spirometry feasibility in 248 children in a busy pediatric pulmonary function laboratory. ${ }^{20}$ In their hands, $82 \%$ of preschool children performing spirometry for the first time were able to complete at least 1 technically acceptable maneuver, but only $54 \%$ were capable of performing spirometry that was acceptable and repeatable based on ATS/ERS preschool spirometry recommendations. Although, the group of children with asthma reported in the cohort by Gaffin et al., did not have forced expiratory volumes or flows that were significantly different from healthy children; $30 \%$ of the in- dividual asthmatic children had evidence of airflow obstruction by $\mathrm{FEV}_{1}$ or $\mathrm{FEF}_{25-75}$ [forced expiratory flow at $25 \%$ to $75 \%$ of expiration (spirometry)], suggesting that preschool spirometry may provide clinically useful information for a substantial subset of individual patients in this age group.

\section{Infants}

Although infants and toddlers are not capable of independently performing spirometric maneuvers, the raisedvolume rapid thoracoabdominal compression (RVRTC) technique can be used to measure forced expiratory flows and volumes in children $\leq 3$ years of age under sedation with chloral hydrate. During the RVRTC maneuver an infant's lungs are inflated to near total lung capacity (TLC) followed by a forced expiration. ${ }^{21-23}$ The RVRTC technique allows generation of flow-volume curves that are similar to adult-type flow-volume curves. RVRTC-forced expiratory flows and volumes have been used to assess infants with bronchiolitis and recurrent wheezing, ${ }^{24,25}$ and bronchodilator responsiveness in healthy infants. ${ }^{26}$ Reference values from healthy infants are published, ${ }^{27}$ and 2 devices to perform infant PFT (iPFT) using the RVRTC method are commercially available.

However, there are several important barriers to using the RVRTC technique to obtain lung function measurements for clinical use. Little data exist regarding the within- and between-occasion repeatability of RVRTC measurements. Performing RVRTC measurements is complex and time consuming, requires sedation of the patient, and must be performed using expensive equipment operated by highly trained personnel. For these reasons, the ability to obtain highquality RVRTC measurements is limited to a small number of laboratories around the world. Published normative data were derived from a relatively small sample size $(n=155)$, limiting its generalizability to populations around the world with different ethnicities as well as social and environmental backgrounds. ${ }^{27}$ Further, longitudinal studies assessing the predictive value of RVRTC lung function values for persistent asthma among infants with recurrent wheezing is lacking. Although published data describing forced expiratory volumes and flows following administration of albuterol in healthy children exist, ${ }^{26}$ a consensus does not yet reached on the definition of a clinical BDR during RVRTC maneuvers. Although infant lung function testing using the RVRTC technique is a powerful research tool, the technical issues summarized above may limit its use as a routine clinical tool in assessing infants and toddlers with wheezing disorders.

\section{Lung Volume Measurements}

\section{Plethysmography}

Lung volume measurements in preschool and school-age children are easily performed using multiple methodologies, including whole-body plethysmography or gas washout techniques. Plethysmographic measurements can be performed using either panting methods (only suitable for older children) or single inspiratory effort technique. ${ }^{28}$ However, there are conflicting reports on the utility of lung volume parameters in children with controlled asthma. ${ }^{29,30}$ This may be due in part to the selection of proper reference data and high variability in measurement of some of the parameters. The literature suggests that in older individuals, static lung 
volume measurement may be abnormal in asthmatic patients and more sensitive than $\mathrm{FEV}_{1}$ to small airway dysfunction. $^{31,32}$ This methodology has been hampered by the need for bulky expensive equipment, lack of portability, and difficulty in performing the maneuver.

Whole-body plethysmography can be performed in infants and toddlers using commercially available equipment to obtain measurements of functional residual capacity (plethysmography) $\left(\mathrm{FRC}_{\text {pleth }}\right)$, residual volume (RV), TLC, and the ratio of RV/TLC. ${ }^{33}$ However, there is very little published data assessing the utility of plethysmographic lung function measures in infants and toddlers with recurrent wheezing to predict asthma. Saito et al. reported that among children less than 3 years old with recurrent wheezing unresponsive to asthma medications, plethysmography revealed mean FRC and RV/TLC measurements greater than 2 z-scores above published normative data. ${ }^{34}$ Unfortunately, the only available published normative plethysmography data ${ }^{35}$ are based on a very small sample size, limiting generalizability of plethysmography measurements in the assessment of infants and toddlers with recurrent wheezing.

\section{Multiple breath inert gas washout}

The multiple breath inert gas washout technique is used to assess lung ventilation inhomogeneity as well as measurement of FRC. The advantage of multiple breath washout is that it is an effort independent technique and thus can be applied from infancy to adulthood using tidal breathing techniques. ${ }^{11,36}$ The lung clearance index (LCI), the cumulative expired volume required to clear the inert gas to $1 / 40$ th of the initial gas concentration from the lungs divided by the FRC, seems to be a useful and sensitive measure of peripheral airway obstruction, especially in cystic fibrosis. ${ }^{37-41}$ Other parameters can also be calculated such as the normalized slopes and moment ratios. The usefulness of these other parameters is limited by the small number of studies and the increasing complexity in understanding what they represent physiologically. The ideal parameter for reporting is elusive at present due to the paucity of data in the different age ranges and disease entities. Several studies have been published suggesting that LCI, moment ratios, as well as other parameters are significantly different in patients suffering from asthma and preschool wheeze. ${ }^{42-46}$ One study has suggested that its utility may be superior to other pulmonary function parameters that are possible to perform in preschool children. ${ }^{47}$ However, further work needs to be done to understand the relevance of abnormalities in LCI and whether it correlates to clinically meaningful outcomes longitudinally. The multiple breath washout methodology is currently available using different commercial devices; however, validation studies comparing different methodologies are lacking and standardization in reporting has not been established.

\section{Airway Resistance Measurements}

\section{Specific airway resistance}

Plethysmographic measurements of sRaw can be obtained during tidal breathing without the need for specialized breathing maneuvers or respiration against an airway occlusion. ${ }^{48}$ sRaw is calculated as the product of FRC and Raw. ${ }^{49}$ This technique has been successfully performed in children as young as age 2 years. ${ }^{50}$ While limited data from a few specialized research centers suggest that sRaw is increased in preschool-age children with recurrent wheezing or asthma compared to healthy children, ${ }^{51-56}$ it has been purported in older subjects to be more sensitive to bronchodilator changes than traditional lung function tests such as spirometry. ${ }^{13,57}$ Further, sRaw has been demonstrated to improve following treatment with inhaled corticosteroids, ${ }^{54}$ leukotriene receptor antagonists, ${ }^{51}$ and $\beta_{2}$-agonists. ${ }^{55,58}$

Despite the appeal of sRaw as a lung function measurement that can be obtained in preschool-age children, there are a number of important limitations to the applicability of this measure in clinical decision making in preschool-age children. A consensus does not exist with regard to standardization of measurement equipment and conditions, and data analysis. Recently, as part of The Asthma UK Initiative, Kirkby et al. proposed reference equations constructed from sRaw data obtained from healthy children ages 3-10 years at 5 European centers. ${ }^{59}$ However, Kirkby et al. caution that their reference equations should only be applied to populations studied using the same methodology as employed in the centers included in their analysis. The development of international consensus recommendations (eg, ATS/ERS) for equipment and methodology to perform sRaw measurements in preschool-age children would facilitate its utility as a lung function measurement technique for clinical use in the diagnosis or monitoring of asthma or wheezing disorders in this age group.

\section{The interrupter technique}

Respiratory tract resistance can be estimated during tidal breathing using the interrupter technique. Based on the assumption that during a brief airway occlusion mouth pressure rapidly equilibrates with alveolar pressure, respiratory Rint is defined as occlusion mouth pressure divided by the airflow measured immediately before an occlusion. ${ }^{60}$ Measurement of Rint using commercially available equipment is possible in most children as young as 3 years old with acceptable withinand between-occasion repeatability. ${ }^{11}$ Using data collected from more than 1,000 children, Merkus et al. recently published robust reference equations to allow better interpretation of Rint measurements obtained from young children. ${ }^{61}$ Several clinical studies have demonstrated higher Rint values among preschool-age children with asthma or recurrent wheezing as compared to healthy controls; however, a large degree of overlap in distribution of Rint between healthy and asthmatic or wheezy infants has been noted. ${ }^{55,62,63}$

Although Rint has been used to estimate the magnitude of change in airflow resistance in response to a bronchodilator, an accepted cut-off to define bronchodilator responsiveness in preschool-age children does not currently exist. ${ }^{11}$ Due to the poor discriminative power of Rint between asthma and health at the individual level, and lack of a defined clinical BDR, the utility of Rint in clinical diagnosis of asthma in preschool-age children is limited. However, with the advent of newly established reference equations, ${ }^{61}$ Rint may prove to be useful to assess response to therapeutic interventions longitudinally.

\section{Forced oscillometry}

The forced oscillation technique (FOT) is a noninvasive lung function test that can be performed during tidal breathing with minimal cooperation from the patient. ${ }^{64} \mathrm{Gi}$ ven the simplicity of the maneuver, the FOT technique is an 
attractive methodology for use in preschool-age children. Unfortunately, the complexity of the mathematic and physics assumptions upon which FOT is based have proven challenging for clinicians and researchers alike to fully understand. Several reviews are available for a more complete description of the underlying principal of FOT. ${ }^{11,64-66}$ Briefly, an oscillatory signal, most commonly pseudorandom at frequencies between 4 and $10 \mathrm{~Hz}$, is applied to the airway opening using a mouthpiece. Flow and pressure are measured at the mouth. Resultant pressure and flow fluctuations at the mouth in response to the applied oscillatory signal are measured. The pressure and flow relationship is described as Xrs, where Xrs is determined by the elastic and inertial properties of the respiratory system. Respiratory resistance (Rrs) represents the total Rrs, of which airway resistance is the most significant.

A recent ATS/ERS statement on PFT in preschool children attempted to standardize FOT measurements by recommending that the optimal measurement frequencies be between 4 and $8 \mathrm{~Hz}^{11}{ }^{11}$ For preschool-age children mean coefficient of variation $(\mathrm{CV} \%)$ and between-test coefficient of repeatability (CR\%) for Rrs between 4 and $8 \mathrm{~Hz}$ are reported between $6 \%$ and $10 \% .{ }^{67-70} \mathrm{~A}$ number of published studies have proposed reference equations for FOT Rrs based on measurements in healthy children. ${ }^{68-76}$ Unfortunately, these reference equations do not use a standard frequency and there is significant variability between studies in equipment and measurement protocols.

Some studies of preschool-age children have reported both greater Xrs and Rrs at one or more frequencies among children with asthma or wheezing, some studies have reported higher Rrs, yet no difference in Xrs in asthmatic or wheezy subjects, whereas other investigators report no differences in either Xrs or Rrs between asthmatic/wheezy subjects and healthy controls. ${ }^{55,68,77,78}$ There is very little longitudinal FOT data in preschool-age children to assess the diagnostic utility of FOT in predicting asthma in young children with recurrent wheezing. Although several studies have proposed criteria to identify bronchodilator responsiveness in preschool-age children, proposed frequency and cutoff values vary significantly between studies. ${ }^{55,67,70,77,79-81}$

\section{Measurements of Airway Inflammation}

\section{Exhaled nitric oxide}

The fractional concentration of exhaled nitric oxide $\left(\mathrm{FE}_{\mathrm{NO}}\right)$ is a proposed biomarker of airway inflammation in asthma. ${ }^{82} \mathrm{FE}_{\mathrm{NO}}$ has repeatedly been shown to be elevated in adults and children with allergic asthma ${ }^{83}$ and rhinitis ${ }^{84}$ but has been minimally studied in infants and toddlers. In adults and school-age children with atopic asthma $\mathrm{FE}_{\mathrm{NO}}$ is correlated with sputum and bronchoalveolar eosinophils, peak flow variability, and bronchial reactivity. ${ }^{85-92} \mathrm{FE}_{\mathrm{NO}}$ decreases following treatment with systemic or inhaled corticosteroids in adults and school-age children with asthma, ${ }^{93}$ and has been shown to have a superior diagnostic accuracy for asthma than conventional diagnostic approaches, including spirometry. ${ }^{85,94-96}$ Several groups have demonstrated in cross-sectional studies that $\mathrm{FE}_{\mathrm{NO}}$ is higher in wheezy infants and toddlers than in healthy controls ${ }^{97-101}$; however, $\mathrm{FE}_{\mathrm{NO}}$ was measured during tidal breathing in all but one of these studies. In a longitudinal study of preschool children (mean enrollment age $>3$ years) elevated tidal breathing $\mathrm{FE}_{\mathrm{NO}}$ was associated with a 3-fold higher risk of respiratory illness over 1 year of follow-up. ${ }^{102}$ Major limitations of tidal breathing $\mathrm{FE}_{\mathrm{NO}}$ measurement in infants/toddlers include nasal nitric oxide contamination because nasal nitric oxide production far exceeds lower airway production and widely variable expiratory flow because $\mathrm{FE}_{\mathrm{NO}}$ measurement is highly flow dependent. ${ }^{103,104}$ Recently, Debley et al. demonstrated in a longitudinal study of wheezy infants/toddlers that higher enrollment flow-regulated singlebreath exhaled nitric oxide levels were associated with a subsequent decline in lung function, increased risk of subsequent treatment with systemic corticosteroids for wheezing exacerbations, and bronchodilator responsiveness. ${ }^{105}$ Further, enrollment single-breath exhaled nitric oxide was superior to lung function and bronchodilator responsiveness as a predictor of wheezing exacerbations during follow-up. Despite its promise as a potential diagnostic test for asthma in infants and preschool-age children, due to the lack of a standardized approach to measurement in this age group and paucity of longitudinal data, $\mathrm{FE}_{\mathrm{NO}}$ is not yet a suitable clinical tool for use in infants and preschool-age children.

\section{Exhaled breath condensate}

Analysis of constituents of exhaled breath may in the future prove useful to noninvasively evaluate the biology of lung or airway diseases. However, even in school-age children and adults the measurement of biomarkers in exhaled breath condensates (EBC) is an immature field with many unresolved methodological challenges. ${ }^{106}$ Although a variety of volatile and nonvolatile compounds have been detected in EBC by many investigators, there is a dearth of data regarding the physiological factors that affect EBC composition. ${ }^{84,107}$ A recent ATS/ERS Task Force report identified the need for studies that assess accuracy and reproducibility of EBC collection and analysis before the widespread introduction of EBC into clinical trials or practice. ${ }^{107}$ Although there are reports of successful breath condensate collection and subsequent measurement of inflammatory mediators within EBC collected from infants and preschool-age children, ${ }^{108-111}$ technical barriers to successful collection of adequate volumes of EBC to allow for assays of potential biomarkers are even more significant in this age range.

\section{Summary}

For school-age children measurement of lung function using spirometry is an indispensible component of the diagnostic approach to asthma and longitudinal monitoring of asthma control. Spirometry provides objective clinical data that are complimentary to an accurate medical history and physical examination for many children with asthma or recurrent wheezing.

A number of additional lung function testing modalities, including RVRTC iPFTs, preschool spirometry, the LCI, specific airway resistance, and forced oscillometry, have shown significant promise in research studies as potential tools for the assessment of infants, toddlers, and preschoolage children with recurrent wheezing. In our opinion, given the availability of commercial devices and published reference equations, preschool spirometry may be clinically useful in identifying airflow obstruction in individual children when 
performed by providers with appropriate expertise and experience. While limited in its ability to distinguish health from disease at the level of the individual, validation studies and reference equations are also sufficient to consider clinical measurement of airflow resistance with Rint to track response to therapeutic interventions longitudinally. At the present time, a lack adequate validation studies, reference data, or commercial devices, and technical complexity limit the clinical utility of RVRTC iPFTs, the LCI, specific airway resistance, and forced oscillometry in the routine assessment of preschool-age children with recurrent wheezing. Finally, there has been great interest in the measurement of $\mathrm{FE}_{\mathrm{NO}}$ to assess lower airway inflammation in patients with asthma. Based on several recent randomized controlled trials, there is insufficient data to support its routine use to titrate inhaled corticosteroids in children with asthma. However, given that $\mathrm{FE}_{\mathrm{NO}}$ is easy to measure in school-age children, it can be measured with clinically approved devices, and sufficient data exist establishing its diagnostic utility in steroid naïve patients, $\mathrm{FE}_{\mathrm{NO}}$ can be recommended as an adjunctive diagnostic tool in children in whom the diagnosis of asthma is unclear despite standard clinical measures.

\section{Author Disclosure Statement}

No competing financial interests exist.

\section{References}

1. National Asthma Education and Prevention Program. Expert Panel Report: Guidelines for the Diagnosis and Management of Asthma Update on Selected Topics-2002. J Allergy Clin Immunol 2002; 110(5 Suppl):S141-S219.

2. Russell NJ, Crichton NJ, Emerson PA, Morgan AD. Quantitative assessment of the value of spirometry. Thorax 1986; 41:360 363.

3. Nair SJ, Daigle KL, DeCuir P, Lapin CD, Schramm CM. The influence of pulmonary function testing on the management of asthma in children. J Pediatr 2005; 147:797-801.

4. Stout JW, Visness CM, Enright P, Lamm C, Shapiro G, Gan VN, et al. Classification of asthma severity in children: the contribution of pulmonary function testing. Arch Pediatr Adolesc Med 2006; 160:844-850.

5. Bacharier LB, Strunk RC, Mauger D, White D, Lemanske RF Jr., Sorkness CA. Classifying asthma severity in children: mismatch between symptoms, medication use, and lung function. Am J Respir Crit Care Med 2004; 170:426-432.

6. Martinez FD. Development of wheezing disorders and asthma in preschool children. Pediatrics 2002; 109(2 Suppl):362-367.

7. Expert Panel Report 3 (EPR-3): Guidelines for the Diagnosis and Management of Asthma-Summary Report 2007. J Allergy Clin Immunol 2007; 120(5 Suppl):S94-S138.

8. Covar RA, Spahn JD, Martin RJ, Silkoff PE, Sundstrom DA, Murphy J, et al. Safety and application of induced sputum analysis in childhood asthma. J Allergy Clin Immunol 2004; 114:575-582.

9. Covar RA, Spahn JD, Murphy JR, Szefler SJ. Progression of asthma measured by lung function in the childhood asthma management program. Am J Respir Crit Care Med 2004; 170:234-241.

10. Ulrik CS, Backer V. Markers of impaired growth of pulmonary function in children and adolescents. Am J Respir Crit Care Med 1999; 160:40-44.

11. Beydon N, Davis SD, Lombardi E, Allen JL, Arets HG, Aurora $\mathrm{P}$, et al. An official American Thoracic Society/European Respiratory Society statement: pulmonary function testing in preschool children. Am J Respir Crit Care Med 2007; 175:13041345.

12. Black J, Baxter-Jones AD, Gordon J, Findlay AL, Helms PJ. Assessment of airway function in young children with asthma: comparison of spirometry, interrupter technique, and tidal flow by inductance plethsmography. Pediatr Pulmonol 2004; 37:548553.

13. Houghton CM, Woodcock AA, Singh D. A comparison of lung function methods for assessing dose-response effects of salbutamol. Br J Clin Pharmacol 2004; 58:134-141.

14. Hamid Q, Song Y, Kotsimbos TC, Minshall E, Bai TR, Hegele RG, et al. Inflammation of small airways in asthma. J Allergy Clin Immunol 1997; 100:44-51.

15. Eigen H, Bieler H, Grant D, Christoph K, Terrill D, Heilman DK, et al. Spirometric pulmonary function in healthy preschool children. Am J Respir Crit Care Med 2001; 163(3 Pt 1):619-623.

16. Nystad W, Samuelsen SO, Nafstad P, Edvardsen E, Stensrud T, Jaakkola JJ. Feasibility of measuring lung function in preschool children. Thorax 2002; 57:1021-1027.

17. Vilozni D, Barak A, Efrati O, Augarten A, Springer C, Yahav Y, et al. The role of computer games in measuring spirometry in healthy and "asthmatic" preschool children. Chest 2005; 128:1146-1155.

18. Zapletal A, Chalupova J. Forced expiratory parameters in healthy preschool children (3-6 years of age). Pediatr Pulmonol 2003; 35:200-207.

19. Stanojevic S, Wade A, Cole TJ, Lum S, Custovic A, Silverman M, et al. Spirometry centile charts for young Caucasian children: the Asthma UK Collaborative Initiative. Am J Respir Crit Care Med 2009; 180:547-552.

20. Gaffin JM, Shotola NL, Martin TR, Phipatanakul W. Clinically useful spirometry in preschool-aged children: evaluation of the 2007 American Thoracic Society Guidelines. J Asthma 2010; 47:762-767.

21. Feher A, Castile R, Kisling J, Angelicchio C, Filbrun D, Flucke R, et al. Flow limitation in normal infants: a new method for forced expiratory maneuvers from raised lung volumes. J Appl Physiol 1996; 80:2019-2025.

22. Turner DJ, Lanteri CJ, LeSouef PN, Sly PD. Improved detection of abnormal respiratory function using forced expiration from raised lung volume in infants with cystic fibrosis. Eur Respir J 1994; 7:1995-1999.

23. Turner DJ, Stick SM, Lesouef KL, Sly PD, LeSouef PN. A new technique to generate and assess forced expiration from raised lung volume in infants. Am J Respir Crit Care Med 1995; 151:1441-1450.

24. Modl M, Eber E, Weinhandl E, Gruber W, Zach MS. Assessment of bronchodilator responsiveness in infants with bronchiolitis. A comparison of the tidal and the raised volume rapid thoracoabdominal compression technique. Am J Respir Crit Care Med 2000; 161(3 Pt 1):763-768.

25. Hayden MJ, Wildhaber JH, LeSouef PN. Bronchodilator responsiveness testing using raised volume forced expiration in recurrently wheezing infants. Pediatr Pulmonol 1998; 26:35-41.

26. Goldstein AB, Castile RG, Davis SD, Filbrun DA, Flucke RL, McCoy KS, et al. Bronchodilator responsiveness in normal infants and young children. Am J Respir Crit Care Med 2001; 164:447-454.

27. Jones M, Castile R, Davis S, Kisling J, Filbrun D, Flucke R, et al. Forced expiratory flows and volumes in infants. Normative data and lung growth. Am J Respir Crit Care Med 2000; 161(2 Pt 1):353-359.

28. Halvorsen T, Skadberg BT, Eide GE, Roksund OD, Bakke P, Thorsen E. Assessment of lung volumes in children and adolescents: comparison of two plethysmographic techniques. $\underline{\text { Clin }}$ Physiol Funct Imaging 2005; 25:62-68.

29. Verini M, Peroni DG, Rossi N, Nicodemo A, De Stradis R, Spagnolo C, et al. Functional assessment of allergic asthmatic 
children while asymptomatic. Allergy Asthma Proc 2006; 27:359-364.

30. Vilozni D, Efrati O, Hakim F, Adler A, Livnat G, Bentur L. FRC measurements using body plethysmography in young children. Pediatr Pulmonol 2009; 44:885-891.

31. Pool JB, Greenough A, Price JF. Abnormalities of functional residual capacity in symptomatic and asymptomatic young asthmatics. Acta Paediatr Scand 1988; 77:419-423.

32. Woolcock AJ, Read J. Improvement in bronchial asthma not reflected in forced expiratory volume. Lancet 1965; 2:1323-1325.

33. Stocks J, Godfrey S, Beardsmore C, Bar-Yishay E, Castile R. Plethysmographic measurements of lung volume and airway resistance. ERS/ATS Task Force on Standards for Infant Respiratory Function Testing. European Respiratory Society/ American Thoracic Society. Eur Respir J 2001; 17:302-312.

34. Saito J, Harris WT, Gelfond J, Noah TL, Leigh MW, Johnson R, et al. Physiologic, bronchoscopic, and bronchoalveolar lavage fluid findings in young children with recurrent wheeze and cough. Pediatr Pulmonol 2006; 41:709-719.

35. Castile R, Filbrun D, Flucke R, Franklin W, McCoy K. Adulttype pulmonary function tests in infants without respiratory disease. Pediatr Pulmonol 2000; 30:215-227.

36. Robinson PD, Goldman MD, Gustafsson PM. Inert gas washout: theoretical background and clinical utility in respiratory disease. Respiration 2009; 78:339-355.

37. Aurora P, Gustafsson P, Bush A, Lindblad A, Oliver C, Wallis $\mathrm{CE}$, et al. Multiple breath inert gas washout as a measure of ventilation distribution in children with cystic fibrosis. Thorax 2004; 59:1068-1073.

38. Aurora P, Bush A, Gustafsson P, Oliver C, Wallis C, Price J, et al. Multiple-breath washout as a marker of lung disease in preschool children with cystic fibrosis. Am J Respir Crit Care Med 2005; 171:249-256.

39. Aurora P, Stanojevic S, Wade A, Oliver C, Kozlowska W, Lum $\mathrm{S}$, et al. Lung clearance index at 4 years predicts subsequent lung function in children with cystic fibrosis. Am J Respir Crit Care Med 2010; PMID:20935113.

40. Gustafsson PM, De Jong PA, Tiddens HA, Lindblad A. Multiple-breath inert gas washout and spirometry versus structural lung disease in cystic fibrosis. Thorax 2008; 63:129-134.

41. Robinson PD, Lindblad A, Gustafsson PM. Comparison of the utility of multiple breath inert gas washout parameters in cystic fibrosis. Thorax 2010; 65:659.

42. Gustafsson PM. Peripheral airway involvement in CF and asthma compared by inert gas washout. Pediatr Pulmonol 2007; 42:168-176.

43. Downie SR, Salome CM, Verbanck S, Thompson B, Berend N, King GG. Ventilation heterogeneity is a major determinant of airway hyperresponsiveness in asthma, independent of airway inflammation. Thorax 2007; 62:684-689.

44. Verbanck S, Schuermans D, Noppen M, Van Muylem A, Paiva M, Vincken W. Evidence of acinar airway involvement in asthma. Am J Respir Crit Care Med 1999; 159(5 Pt 1):1545-1550.

45. Verbanck S, Schuermans D, Paiva M, Vincken W. Nonreversible conductive airway ventilation heterogeneity in mild asthma. J Appl Physiol 2003; 94:1380-1386.

46. Macleod KA, Horsley AR, Bell NJ, Greening AP, Innes JA, Cunningham S. Ventilation heterogeneity in children with well controlled asthma with normal spirometry indicates residual airways disease. Thorax 2009; 64:33-37.

47. Sonnappa S, Bastardo CM, Wade A, Saglani S, McKenzie SA, Bush A, et al. Symptom-pattern phenotype and pulmonary function in preschool wheezers. I Allergy Clin Immunol 2010; 126:519-526.

48. Nielsen KG. Plethysmographic specific airway resistance. Paediatr Respir Rev 2006; 7 Suppl 1:S17-S19.

49. Dab I, Alexander F. A simplified approach to the measurement of specific airway resistance. Pediatr Res 1976; 10:998-999.
50. Bisgaard H, Nielsen KG. Plethysmographic measurements of specific airway resistance in young children. Chest 2005; 128:355-362.

51. Bisgaard H, Nielsen KG. Bronchoprotection with a leukotriene receptor antagonist in asthmatic preschool children. Am J Respir Crit Care Med 2000; 162:187-190.

52. Klug B, Bisgaard H. Lung function and short-term outcome in young asthmatic children. Eur Respir J 1999; 14:1185-1189.

53. Nielsen KG, Bisgaard H. Lung function response to cold air challenge in asthmatic and healthy children of 2-5 years of age. Am J Respir Crit Care Med 2000; 161:1805-1809.

54. Nielsen KG, Bisgaard $H$. The effect of inhaled budesonide on symptoms, lung function, and cold air and methacholine responsiveness in 2- to 5-year-old asthmatic children. Am J Respir Crit Care Med 2000; 162(4 Pt 1):1500-1506.

55. Nielsen KG, Bisgaard H. Discriminative capacity of bronchodilator response measured with three different lung function techniques in asthmatic and healthy children aged 2 to 5 years. Am J Respir Crit Care Med 2001; 164:554-559.

56. Buhr W, Jorres R, Knapp M, Berdel D. Diagnostic value of body plethysmographic parameters in healthy and asthmatic young children is not influenced by breathing frequency. Pediatr Pulmonol 1990; 8:23-28.

57. Houghton CM, Woodcock AA, Singh D. A comparison of plethysmography, spirometry and oscillometry for assessing the pulmonary effects of inhaled ipratropium bromide in healthy subjects and patients with asthma. Br J Clin Pharmacol 2005; 59:152-159.

58. Nielsen KG, Bisgaard H. Bronchodilation and bronchoprotection in asthmatic preschool children from formoterol administered by mechanically actuated dry-powder inhaler and spacer. Am J Respir Crit Care Med 2001; 164:256-259.

59. Kirkby J, Stanojevic S, Welsh L, Lum S, Badier M, Beardsmore $\mathrm{C}$, et al. Reference equations for specific airway resistance in children: the Asthma UK initiative. Eur Respir J 2010; 36:622629.

60. Beydon N. Interrupter resistance: what's feasible? Paediatr Respir Rev 2006; 7 Suppl 1:S5-S7.

61. Merkus PJ, Stocks J, Beydon N, Lombardi E, Jones M, McKenzie $\mathrm{SA}$, et al. Reference ranges for interrupter resistance technique: the Asthma UK Initiative. Eur Respir J 2010; 36:157-163.

62. Brussee JE, Smit HA, Koopman LP, Wijga AH, Kerkhof M, Corver $\mathrm{K}$, et al. Interrupter resistance and wheezing phenotypes at 4 years of age. Am J Respir Crit Care Med 2004; 169:209-213.

63. McKenzie SA, Bridge PD, Healy MJ. Airway resistance and atopy in preschool children with wheeze and cough. Eur Respir I 2000; 15:833-838.

64. Frey U. Forced oscillation technique in infants and young children. Paediatr Respir Rev 2005; 6:246-254.

65. Oostveen E, MacLeod D, Lorino H, Farre R, Hantos Z, Desager $\mathrm{K}$, et al. The forced oscillation technique in clinical practice: methodology, recommendations and future developments. Eur Respir J 2003; 22:1026-1041.

66. Marchal F, Schweitzer C, Thuy LV. Forced oscillations, interrupter technique and body plethysmography in the preschool child. Paediatr Respir Rev 2005; 6:278-284.

67. Ducharme FM, Davis GM. Respiratory resistance in the emergency department: a reproducible and responsive measure of asthma severity. Chest 1998; 113:1566-1572.

68. Hellinckx J, De Boeck K, Bande-Knops J, van der PM, Demedts M. Bronchodilator response in 3-6.5 years old healthy and stable asthmatic children. Eur Respir J 1998; 12:438-443.

69. Klug B, Bisgaard H. Specific airway resistance, interrupter resistance, and respiratory impedance in healthy children aged 2-7 years. Pediatr Pulmonol 1998; 25:322-331.

70. Malmberg LP, Pelkonen A, Poussa T, Pohianpalo A, Haahtela $\mathrm{T}$, Turpeinen M. Determinants of respiratory system input 
impedance and bronchodilator response in healthy Finnish preschool children. Clin Physiol Funct Imaging 2002; 22:64-71.

71. Ducharme FM, Davis GM, Ducharme GR. Pediatric reference values for respiratory resistance measured by forced oscillation. Chest 1998; 113:1322-1328.

72. Duiverman EJ, Clement J, van de Woestijne KP, Neijens HJ, van den Bergh AC, Kerrebijn KF. Forced oscillation technique. Reference values for resistance and reactance over a frequency spectrum of $2-26 \mathrm{~Hz}$ in healthy children aged $2.3-12.5$ years. Bull Eur Physiopathol Respir 1985; 21:171-178.

73. Hordvik NL, Konig P, Morris DA, Kreutz C, Pimmel RL. Normal values for forced oscillatory respiratory resistance in children. Pediatr Pulmonol 1985; 1:145-148.

74. Lebecque P, Desmond K, Swartebroeckx Y, Dubois P, Lulling J, Coates A. Measurement of respiratory system resistance by forced oscillation in normal children: a comparison with spirometric values. Pediatr Pulmonol 1991; 10:117122.

75. Solymar L, Aronsson PH, Bake B, Bjure J. Respiratory resistance and impedance magnitude in healthy children aged $2-18$ years. Pediatr Pulmonol 1985; 1:134-140.

76. Stanescu D, Moavero NE, Veriter C, Brasseur L. Frequency dependence of respiratory resistance in healthy children. J Appl Physiol 1979; 47:268-272.

77. Marotta A, Klinnert MD, Price MR, Larsen GL, Liu AH. Impulse oscillometry provides an effective measure of lung dysfunction in 4-year-old children at risk for persistent asthma. J Allergy Clin Immunol 2003; 112:317-322.

78. Thamrin C, Gangell CL, Udomittipong K, Kusel MM, Patterson $\mathrm{H}, \mathrm{Fukushima} \mathrm{T}$, et al. Assessment of bronchodilator responsiveness in preschool children using forced oscillations. Thorax 2007; 62:814-819.

79. Delacourt C, Lorino H, Herve-Guillot M, Reinert P, Harf A, Housset B. Use of the forced oscillation technique to assess airway obstruction and reversibility in children. Am J Respir Crit Care Med 2000; 161(3 Pt 1):730-736.

80. Delacourt C, Lorino H, Fuhrman C, Herve-Guillot M, Reinert P, Harf A, et al. Comparison of the forced oscillation technique and the interrupter technique for assessing airway obstruction and its reversibility in children. Am J Respir Crit Care Med 2001; 164:965-972.

81. Lebecque P, Stanescu D. Respiratory resistance by the forced oscillation technique in asthmatic children and cystic fibrosis patients. Eur Respir J 1997; 10:891-895.

82. Kharitonov SA, Barnes PJ. Exhaled markers of pulmonary disease. Am J Respir Crit Care Med 2001; 163:1693-1722.

83. Taylor DR, Pijnenburg MW, Smith AD, de Jongste JC. Exhaled nitric oxide measurements: clinical application and interpretation. Thorax 2006; 61:817-827.

84. Kostikas K, Koutsokera A, Papiris S, Gourgoulianis KI, Loukides S. Exhaled breath condensate in patients with asthma: implications for application in clinical practice. Clin Exp Allergy 2008; 38:557-565.

85. Dupont LJ, Rochette F, Demedts MG, Verleden GM. Exhaled nitric oxide correlates with airway hyperresponsiveness in steroid-naive patients with mild asthma. Am J Respir Crit Care Med 1998; 157(3 Pt 1):894-898.

86. Gibson PG, Henry RL, Thomas P. Noninvasive assessment of airway inflammation in children: induced sputum, exhaled nitric oxide, and breath condensate. Eur Respir J 2000; 16:10081015.

87. Grootendorst DC, Sont JK, Willems LN, Kluin-Nelemans JC, Van Krieken JH, Veselic-Charvat M, et al. Comparison of inflammatory cell counts in asthma: induced sputum vs bronchoalveolar lavage and bronchial biopsies. Clin Exp Allergy 1997; 27:769-779.

88. Jatakanon A, Kharitonov S, Lim S, Barnes PJ. Effect of differing doses of inhaled budesonide on markers of airway inflammation in patients with mild asthma. Thorax 1999; 54:108-114.
89. Jatakanon A, Lim S, Kharitonov SA, Chung KF, Barnes PJ. Correlation between exhaled nitric oxide, sputum eosinophils, and methacholine responsiveness in patients with mild asthma. Thorax 1998; 53:91-95.

90. Kharitonov SA, Yates DH, Barnes PJ. Inhaled glucocorticoids decrease nitric oxide in exhaled air of asthmatic patients. Am J Respir Crit Care Med 1996; 153:454-457.

91. Lim S, Jatakanon A, John M, Gilbey T, O'connor BJ, Chung KF, et al. Effect of inhaled budesonide on lung function and airway inflammation. Assessment by various inflammatory markers in mild asthma. Am J Respir Crit Care Med 1999; 159:22-30.

92. Warke TJ, Fitch PS, Brown V, Taylor R, Lyons JD, Ennis M, et al. Exhaled nitric oxide correlates with airway eosinophils in childhood asthma. Thorax 2002; 57:383-387.

93. Yates DH, Kharitonov SA, Robbins RA, Thomas PS, Barnes PJ. Effect of a nitric oxide synthase inhibitor and a glucocorticosteroid on exhaled nitric oxide. Am J Respir Crit Care Med 1995; 152:892-896.

94. Malmberg LP, Pelkonen AS, Haahtela T, Turpeinen M. Exhaled nitric oxide rather than lung function distinguishes preschool children with probable asthma. Thorax 2003; 58:494-499.

95. Sivan Y, Gadish T, Fireman E, Soferman R. The use of exhaled nitric oxide in the diagnosis of asthma in school children. J Pediatr 2009; 155:211-216.

96. Smith AD, Cowan JO, Filsell S, McLachlan C, Monti-Sheehan G, Jackson P, et al. Diagnosing asthma: comparisons between exhaled nitric oxide measurements and conventional tests. Am J Respir Crit Care Med 2004; 169:473-478.

97. Baraldi E, Dario C, Ongaro R, Scollo M, Azzolin NM, Panza N, et al. Exhaled nitric oxide concentrations during treatment of wheezing exacerbation in infants and young children. Am J Respir Crit Care Med 1999; 159(4 Pt 1):1284-1288.

98. Wildhaber JH, Hall GL, Stick SM. Measurements of exhaled nitric oxide with the single-breath technique and positive expiratory pressure in infants. Am J Respir Crit Care Med 1999; 159:74-78.

99. Gabriele C, Nieuwhof EM, Van Der Wiel EC, Hofhuis W, Moll HA, Merkus PJ, et al. Exhaled nitric oxide differentiates airway diseases in the first two years of life. Pediatr Res 2006; 60:461465.

100. Moeller A, Diefenbacher C, Lehmann A, Rochat M, BrooksWildhaber J, Hall GL, et al. Exhaled nitric oxide distinguishes between subgroups of preschool children with respiratory symptoms. J Allergy Clin Immunol 2008; 121:705-709.

101. Meyts I, Proesmans M, Van G, V, Hoppenbrouwers K, De Boeck K. Tidal off-line exhaled nitric oxide measurements in a pre-school population. Eur J Pediatr 2003; 162:506-510.

102. Beigelman A, Mauger DT, Phillips BR, Zeiger RS, Taussig LM, Strunk RC, et al. Effect of elevated exhaled nitric oxide levels on the risk of respiratory tract illness in preschool-aged children with moderate-to-severe intermittent wheezing. Ann Allergy Asthma Immunol 2009; 103:108-113.

103. Franklin PJ, Turner SW, Mutch RC, Stick SM. Measuring exhaled nitric oxide in infants during tidal breathing: methodological issues. Pediatr Pulmonol 2004; 37:24-30.

104. Franklin PJ, Turner SW, Mutch RC, Stick SM. Comparison of single-breath and tidal breathing exhaled nitric oxide levels in infants. Eur Respir J 2004; 23:369-372.

105. Debley JS, Stamey DC, Cochrane ES, Gama KL, Redding GJ. Exhaled nitric oxide, lung function, and exacerbations in wheezy infants and toddlers. I Allergy Clin Immunol 2010; 125:1228-1234.

106. Rosias PP, Dompeling E, Hendriks HJ, Heijnens JW, Donckerwolcke RA, Jobsis Q. Exhaled breath condensate in children: pearls and pitfalls. Pediatr Allergy Immunol 2004; 15:4-19.

107. Horvath I, Hunt J, Barnes PJ, Alving K, Antczak A, Baraldi E, et al. Exhaled breath condensate: methodological recommendations and unresolved questions. Eur Respir J 2005; 26:523548. 
108. Moeller A, Franklin P, Hall GL, Horak F Jr., Wildhaber JH, Stick SM. Measuring exhaled breath condensates in infants. Pediatr Pulmonol 2006; 41:184-187.

109. Latzin P, Beck-Ripp J, Hartl D, Bartenstein A, Noss J, Griese M. 8-Isoprostane in nasally exhaled breath condensate in different pediatric lung diseases. Eur J Med Res 2007; 12:21-25.

110. Hitka P, Cerny M, Vizek M, Wilhelm J, Zoban P. Assessment of exhaled gases in ventilated preterm infants. Physiol Res 2004; 53:561-564

111. Rosias PP, Robroeks CM, van de Kant KD, Rijkers GT, Zimmermann LJ, van Schayck CP, et al. Feasibility of a new method to collect exhaled breath condensate in pre-school children. Pediatr Allergy Immunol 2009; 21(1 Pt 2):e235-e244.
Address correspondence to: Padmaja Subbarao, M.D., M.Sc. (Epid), FRCP(C) Hospital for Sick Children University of Toronto Room 4534, Gerrard Wing 555 University Ave. Toronto, ON M5G 1X8 Canada

E-mail: padmaja.subbarao@sickkids.ca

Received for publication November 22, 2010; accepted after revision February 4, 2011. 
This article has been cited by:

1. Margaret Rosenfeld, Guest Editor . 2011. Clinical Applications of Pediatric Pulmonary Function Testing-Introduction to the Series. Pediatric Allergy, Immunology, and Pulmonology 24:2, 55-56. [Citation] [Full Text HTML] [Full Text PDF] [Full Text PDF with Links] 